\title{
ANALYSIS OF AMBULANCE DIVERSION POLICIES FOR A LARGE-SIZE HOSPITAL
}

\author{
Adrian Ramirez \\ John W. Fowler \\ Teresa $\mathrm{Wu}$ \\ Dept. of Industrial Systems and Operations Engineering \\ Arizona State University \\ Tempe, AZ 85287, USA
}

\begin{abstract}
The overcrowding of Emergency Departments (EDs) is a well-known problem that has been analyzed on multiple occasions. Queuing theory and simulation have been applied extensively to specific ED situations, such as staff planning, waiting time reduction and capacity investment. However, there are remaining problems in the EDs that need more study. One of them is the ambulance diversion, which may cause a delay in the treatment of urgent patients therefore jeopardizing their welfare. Since ED are complex system and setting the diversion state in EDs is a subjective decision, a detailed modeling and analysis of cause and effects of such a decision is beneficial. In this research, we build a case-study and analyze the impact of diversion policies in various performance measures of the ED through a designed experiment using a discrete-event simulation model.
\end{abstract}

\section{INTRODUCTION}

During the last decade, national expenditures in healthcare in the United States have increased from 13.5\% of the GDP to $16.2 \%$ in 2007, and is projected to reach $18 \%$ by 2012 according to the Centers for Medicare and Medicaid Services of the United States Department of Health and Human Services (HHS 2009). This is one reason why the Institute of Medicine and the National Academy of Engineering suggest building partnerships in the healthcare system in order to obtain more effective results (NAE/IOM 2005).

In addition to increasing healthcare expenditures, the healthcare system faces problems in different areas, including the Emergency Department (US General Accounting Office-GAO- 2003). In the report prepared for the U.S. Senate by the GAO, they highlighted serious issues in EDs, such as long waiting times, patients that Leave Without Treatment (LWOT), boarding and ambulance diversion.

This report defines boarding as the state of patients waiting in the ED to be transferred to an inpatient unit, which does not have any available bed at that time. Patients LWOT are those who decide to leave the ED after triage but before seeing a doctor. Ambulance Diversion (AD) is the request made by ED managers facing the overcrowding problem to bypass their facilities for those patients that would have been taken to that ED. This last problem is perhaps the one that has received least attention from the engineering community.

The performance of nation's EDs regarding diversion is quite concerning. The GAO found that 2 of every 3 hospitals reported ambulances being diverted to other hospitals at some point in fiscal year 2001. Furthermore, about 1 of every 10 EDs reported being on diversion status for more than 20 percent of the year. An investigation by Associated Press (2006) shows that emergency-care systems are at its "breaking point" and half a million times a year-about once every minute- an ambulance is diverted.

Despite the number of papers in the medical and engineering literature analyzing the ED problems, there is still a lack of literature dealing with the diversion situation from a quantitative standpoint. It can be found in literature studies about waiting time reduction, LWOT or staffing planning using techniques like queuing theory, systems dynamics and discrete-event simulation (Broyles and Cochran 2007; Ferrin, Miller, and McBroom 2007; Roche and Cochran 2007; Brailsford 2008; Kolb et al. 2008; Medeiros, Swenson, and DeFlitch 2008), but few papers focuses on the design of diversion policies. However, 
simulation could be used with other quantitative methods to analyze different problems, including ambulance diversion in regional Healthcare Delivery Networks (Ramirez, Fowler, and Wu 2009).

Qualitative medical literature exists about AD and its relation with other factors and problems. For instance, it is necessary to remember that $\mathrm{AD}$ was not considered as a problem initially, but rather as a solution to reduce the congestion in overcrowded EDs (Asplin 2003). However, AD causes delays in initiating the treatment on emergent patients by transporting them to a further facility, which may compromise the integrity and welfare of the most ill patients (Upfold 2002). Even though diverted ambulances may not represent significant lost revenue (McConnell et al. 2006), it is still a public health problem due to the possible negative effect on the health of those patients being diverted.

This paper provides an analysis of different factors found in the EDs, including the diversion state trigger and their impact in various performance measures, such as waiting time, time on diversion and LWOT percentage, considering a model of a large-size hospital. The rest of the paper is structured as follows, Section 2 explains the methodology used in this research, Section 3 describes the simulation model of the hospital, Section 4 shows the experimentation plan and results for Phase 1, Section 5 explains Phase 2 experimentation and results and finally Section 5 provides some conclusions and ideas for future research.

\section{METHODOLOGY}

\subsection{Objective}

The objective of this research is to analyze the effects of the setting of the ED, the number of beds in the ED and the diversion state trigger on various performance measures of the emergency system, such as the waiting time, the LWOT percentage and especially on the percentage of time on diversion, considering a large-size hospital.

The ED settings being considered are a "Regular ED" where all the patients, regardless of their condition, will be treated in a bed; and a "Fast-Track ED", where patients with a high level of trauma will be seen in a bed while the less ill can receive attention in chairs or less-equipped beds. Even though the beds indicate the capacity of the system, they are an expensive resource in the ED and it is not a trivial decision to invest in them, usually other options are preferred.

The trigger of the diversion status in an ED is a subjective decision and so far there is little evidence of the impact of that decision on other performance measures, therefore they are taken into account to analyze the results of varying this threshold.

\subsection{Simulation Model}

A simulation model of a fictitious large-size hospital was built for this research, which not only considers the ED, but also other inpatient units that affect the operations of the emergency unit. Literature shows that two of the main reasons of setting the diversion status on is the number of patients boarding and the capacity of wards highly demanded by ED patients (Huang 2004); therefore, it is important to consider the transference of patients in order to mimic more accurately the real system.

Few papers describe and provide information about the complexity of a hospital and the ED operations. Two of those papers that can be found in the literature correspond to the same main author. Cochran and Bharti (2006) analyze the operations of a large-size hospital with an ED and 12 inpatient units. This paper describes the transferences of patients between units and provides enough information to replicate the model. On the other hand, the analysis of an ED can be found in Cochran and Roche (2009), which provides detailed information of an ED belonging to a large-size hospital of the same region of the other paper. These two papers are the basis for building two versions of a simulation model that captures the complexity of the ED operations and its interaction with other units in a large-size hospital. The two versions are associated with the ED setting: "Regular ED" and "Fast-Track ED".

\subsection{Experimentation}

The simulation models built representing the whole hospital with detailed representation of the ED operations are subject to experimentation considering the factors described in the objective. For this purpose, a two-level factorial design is implemented to analyze the response regarding waiting time, number of patients in queue, LWOT and diversion statistics.

Then, a second experiments is run using the best ED setting design and number of beds obtained in Part 1 . Those factors are fixed and a larger number of diversion thresholds will be tested to analyze the changes in the results. 


\section{MODEL BUILDING}

\subsection{Model Overview}

As described previously, the model built for this research is derived from two papers which describes the operations of a large-size hospital and an emergency department. The logic for the general flow of patients through the hospital was based on Cochran and Bharti (2006). This paper provides information about twelve inpatient units, such as capacity, length of stay, transfer probabilities and non-emergency admissions. On the other hand, the data for the ED was based on Cochran and Roche (2009). The input data based on this paper comprises the arrival pattern of emergency patients, acuity mix and length of stay in the ED. In addition, the logic to divert ambulances and patients leaving without treatment are incorporated to the model. Figure 1 shows the general scheme of the model containing an ED and 12 inpatient units: Pediatrics (PEDS), Pediatric Intensive Care Unit (PICU), Medical Intensive Care Unit (MICU), Surgical Transition Intensive Care Unit (STICU), Telemetry 1 (TELE 1), Telemetry 2 (TELE 2), Telemetry 3 (TELE 3), Oncology (ONCO), Gynecology (GYN), Orthopedics (ORTHO), Renal and Diabetic Unit (RENAL) and General Surgery (SURG). There are three general types of arrivals: Emergency Arrivals, which can be by Ambulance or Walk-Ins, Direct Admissions and Surgical Admissions. Transference from the ED to any inpatient unit, as well as between inpatient units is allowed. In addition to discharges and transfers, there are another two modes of quitting the ED, one is by leaving without treatment (LWOT) and the other is by being diverted, which only applies to ambulance arrivals.

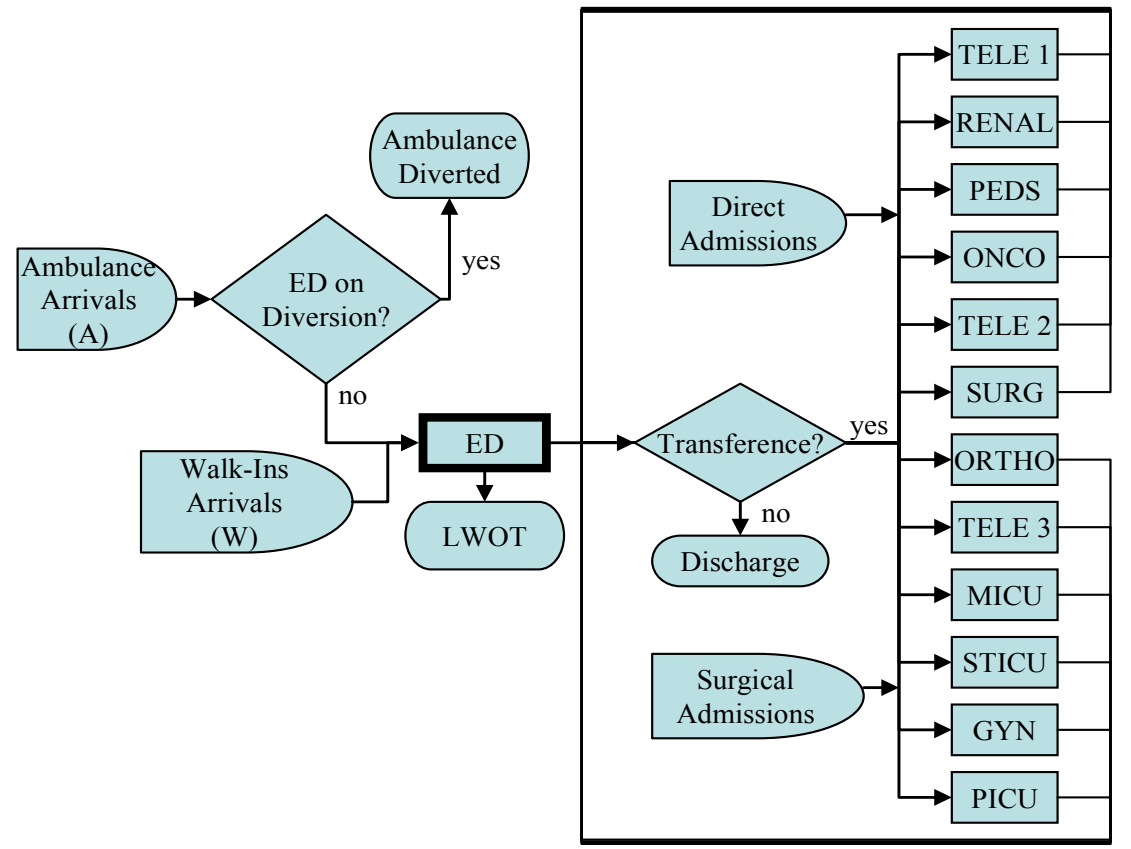

Figure 1: General flow of a large-size hospital

The patients arriving to the ED by any mode are classified into one of five trauma levels: 1, 2, 3, 4 and 5. Level 1 is the most severe state and requires immediate attention, while Level 5 are the less ill patients which can wait longer. Actually, most of patients classified as Level 5 should use another healthcare resource instead of an ED in order to avoid congestion. The model described before has two versions, the "Regular ED" and the "Fast-Track ED".

In the "Regular ED" (shown in Figure 2), all patients receive treatment in a bed highly equipped. However, there is a priority based on the level of trauma to receive attention. Levels 1 and 2 receive high priority, Level 3 has medium priority and Levels 4 and 5 have low priority. After receiving treatment, patients can be either discharged or transferred to an inpatient unit. If it is determined that a patient needs to be transferred but the recipient unit does not have an available bed, the patient will wait until a bed is free. Meanwhile, the patient occupies the same bed in the ED; this is the boarding state. Note that patients can renege from the ED queue, meaning that they are leaving without treatment, however, the restriction is that only patients of Level 3 that arrived walking-in, and all patients of Levels 4 and 5 are allowed to leave the ED without receiving treatment. 


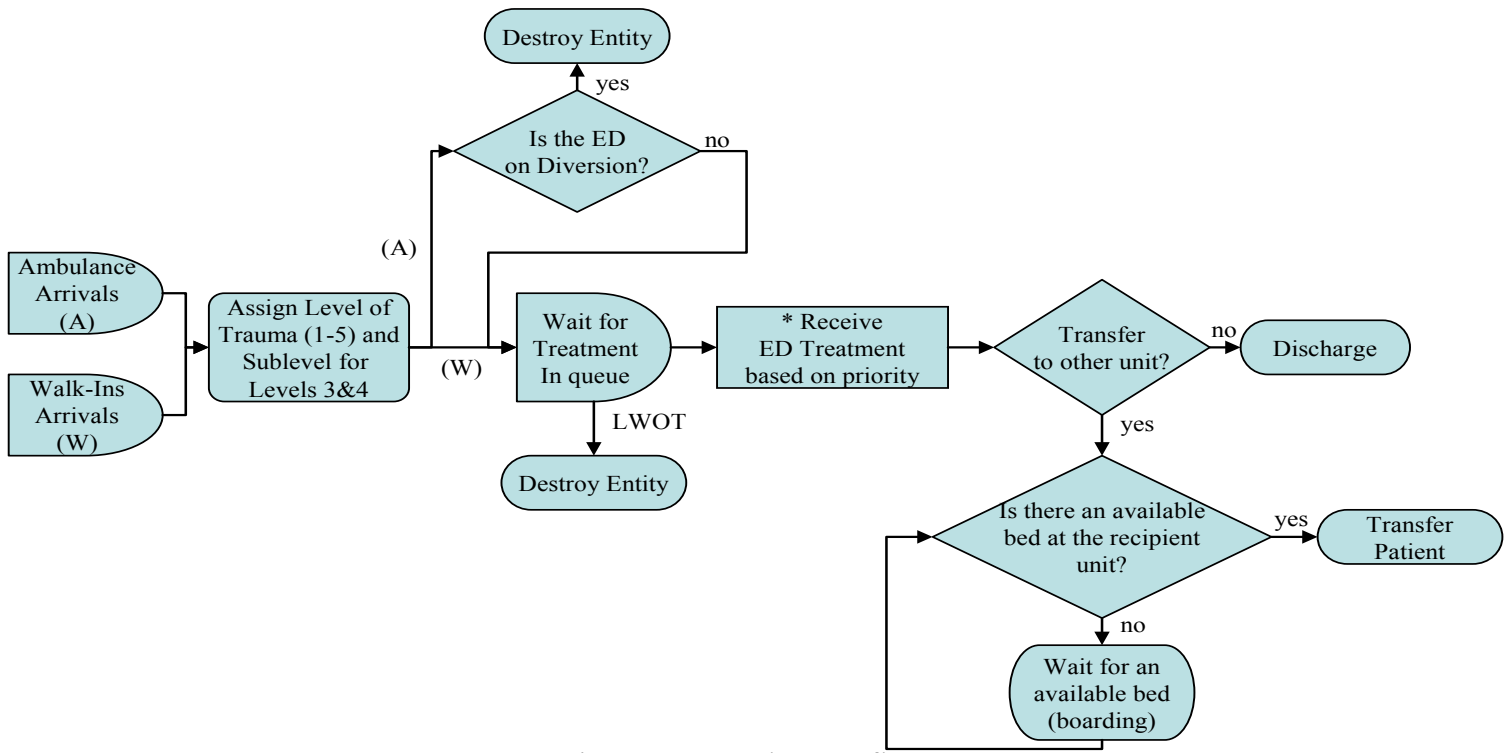

Figure 2: Regular ED flow

The other version of the model shown in Figure 3 considers a "Fast-Track ED". In this setting, the patients split according to their level of trauma. Patients requiring urgent care (Levels 1, 2 and 3) will go to the area where a bed is assigned to receive treatment. At this point, patients of Levels 1 and 2 receive high priority and Level 3 has medium priority. On the other hand, patients with less need will go to a fast-track area where they can wait for a treatment that can be received using different resources, such as chairs or less-equipped beds. After treatment, patients can be discharged or transferred. The rule for LWOT is the same than in the "Regular ED".

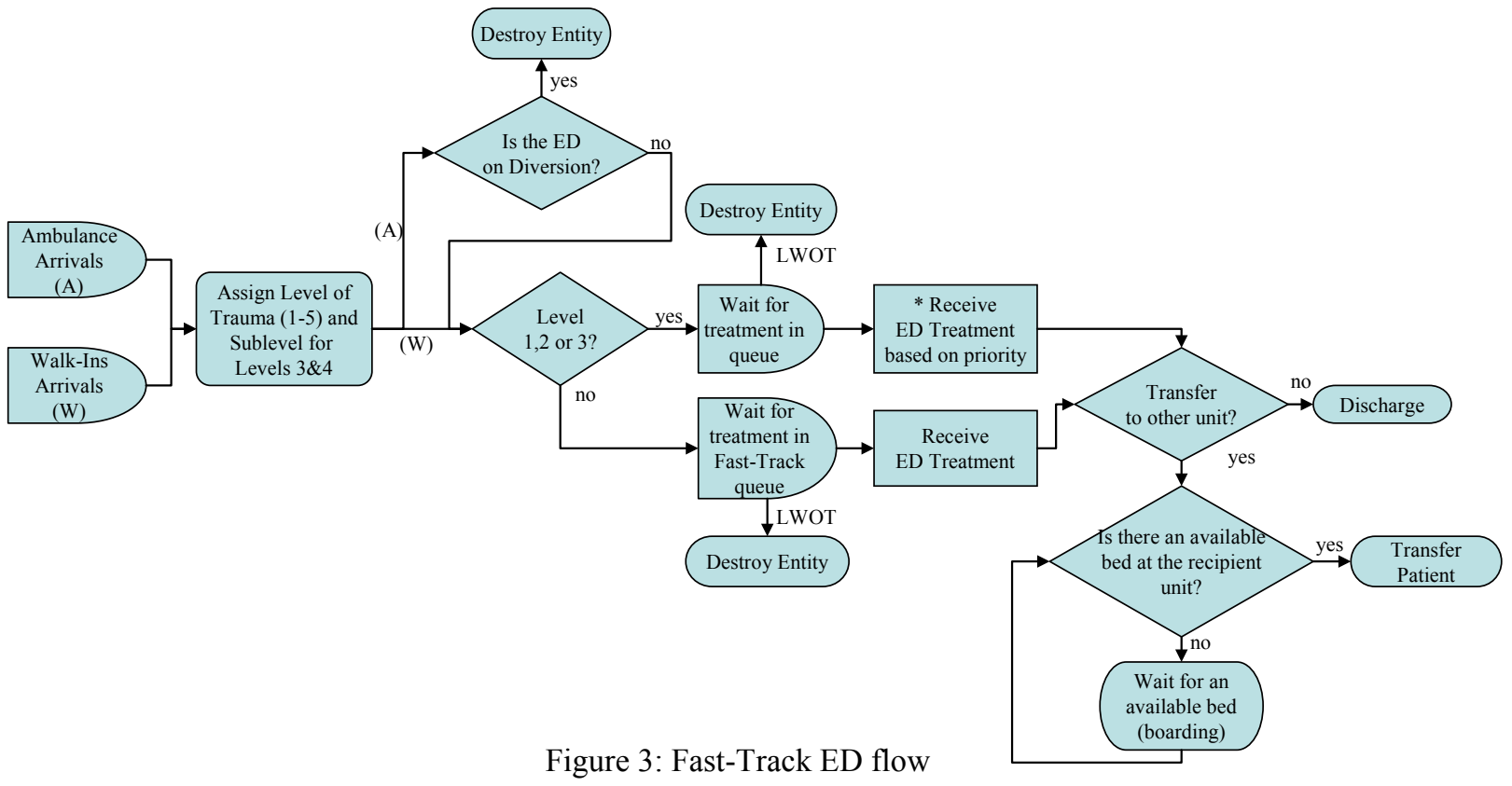

In some simulation models, LWOT is modeled as a decision made at the entry level of the entity regarding joining or not the system. However, this logic does not allow those patients to affect the congestion of the system. In the model shown in this paper, a LWOT routine starts every simulated hour. This routine will look up the number of patients in the queue and will remove a proportion of the entities according to this state. The more patients the queue has, the more patients will be removed. 
The diversion logic works as follows. Every time an ambulance arrives, the diversion status of the ED is observed. If the current status is on diversion, then the entity will be sent to another hospital, which in the simulation means that it will be destroyed. Otherwise the patient will enter the system and the queue length in the ED is observed to determine if the diversion state should be set to "ON". This decision is based on a threshold on the number of patients waiting for treatment. If the diversion state is set $\mathrm{ON}$, it will remain $\mathrm{ON}$ for 30 minutes and then a reevaluation is made in the next ambulance arrival. Figure 4 shows the diversion logic.

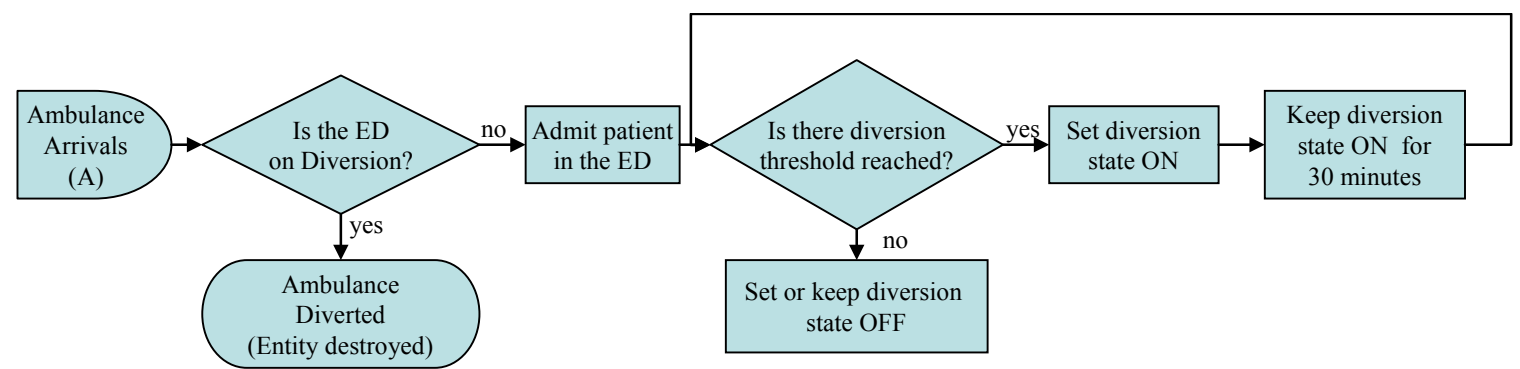

Figure 4: Diversion logic

\subsection{Input Data}

Arrival rates for Direct and Surgical Admissions and their inpatient destinations are assumed to follow a Poisson process. However, the rate of direct admissions depends of the day of the week and time of the day. Table 1 shows the mean arrival rate per hour of these types of patients.

Table 1: Pattern of Direct Arrivals

\begin{tabular}{|l|l|c|}
\hline \multicolumn{1}{|c|}{ Day } & \multicolumn{1}{c|}{ Time } & Mean Arrival Rate \\
\hline MTWTF & $7 \mathrm{am}-11 \mathrm{am}$ & 3.05 \\
\hline MTWTF & $11 \mathrm{am}-3 \mathrm{pm}$ & 3.65 \\
\hline MTWTF & $3 \mathrm{pm}-7 \mathrm{pm}$ & 2.15 \\
\hline Sat \& Sun & $8 \mathrm{am}-12 \mathrm{pm}$ & 1.5 \\
\hline
\end{tabular}

On the other hand, the ED arrival rates have a pattern depending on the hour of the day. The peak time occurs between $9 \mathrm{am}$ to $10 \mathrm{pm}$. This pattern will be used in the form of a multiplicative index to obtain the mean arrival rate per hour. The average number of arrivals to the ED per year is 55863 patients, implying an average approximately of 6.4 arrivals per hour before applying the multiplicative index.

Note that it is important to distinguish the arrival mode of the patients, which we are assuming to be of two types: ambulance or walk-in. Some papers (GAO Report 2003; McConnell et al. 2006; Burt, McCaig, and Valverde 2006) show that about $15 \%$ of all arrivals to the ED are made by ambulance. This percentage is used to create the ambulance arrivals stream and the rest will be part of the walk-ins. Table 2 shows the pattern of arrival rates to the ED used in the model, which are assumed to follow a Poisson process.

Table 2. Pattern of Arrivals to the ED

\begin{tabular}{|l|c|c|c|c|}
\hline $\begin{array}{l}\text { Time of the } \\
\text { Day }\end{array}$ & $\begin{array}{l}\text { Multiplicative } \\
\text { Index }\end{array}$ & $\begin{array}{l}\text { Mean Arrival } \\
\text { Rate }\end{array}$ & $\begin{array}{l}\text { Mean Ambulance } \\
\text { Arrival Rate }\end{array}$ & $\begin{array}{l}\text { Mean Walk-In } \\
\text { Arrival Rate }\end{array}$ \\
\hline 0am - 3am & 0.6 & 3.8 & 0.6 & 3.2 \\
\hline 3am - 7am & 0.4 & 2.6 & 0.4 & 2.2 \\
\hline 7am - 9am & 0.84 & 5.4 & 0.8 & 4.6 \\
\hline 9am - 10pm & 1.32 & 8.4 & 1.3 & 7.1 \\
\hline 10pm - 12pm & 1 & 6.4 & 0.9 & 5.5 \\
\hline
\end{tabular}

The main resources modeled in the hospital are the beds for every unit. The LOS for the non-ED areas depends on the arrival type of the patient: ED Patient or Non-ED Patient. Table 3 shows the number of beds and mean LOS in every inpatient unit, which is assumed to be exponential as justified in Cochran and Bharti (2006). 
Table 3: Number of Beds and LOS in inpatient units

\begin{tabular}{|l|c|c|c|}
\hline \multicolumn{1}{|c|}{ Unit } & Beds & $\begin{array}{c}\text { ED-Patients LOS } \\
\text { (hours) }\end{array}$ & $\begin{array}{c}\text { Non-ED Patients } \\
\text { LOS (hours) }\end{array}$ \\
\hline PEDS & 53 & 59.55 & 56.11 \\
\hline PICU & 12 & 71.24 & 57.56 \\
\hline MICU & 28 & 64.2 & 53.7 \\
\hline STICU & 24 & 131 & 111 \\
\hline TELE 1 & 36 & 72.4 & 77.9 \\
\hline TELE 2 & 36 & 88.2 & 93 \\
\hline TELE 3 & 21 & 62.4 & 23.1 \\
\hline ONCO & 36 & 88.7 & 96 \\
\hline GYN & 30 & 62.3 & 45.6 \\
\hline ORTHO & 32 & 86.7 & 63.2 \\
\hline RENAL & 36 & 85.5 & 78.9 \\
\hline SURG & 32 & 91.5 & 70.1 \\
\hline
\end{tabular}

The length of stay in the ED depends on the level of trauma of the patients. As mentioned before, the levels goes from 1 to 5, however, levels 3 and 4 have sublevels, five and two, respectively. The existence of sublevels is related to the different paths or requirements that some patients have (lab tests, procedures, behavior health problem, observation, etc.). The estimation of the percentage of patients belonging to different levels of trauma is shown in Table 4 (Burt, McCaig, and Valverde 2006).

Table 4. Percentage of Patients Corresponding to Each Level Based on Arrival Mode

\begin{tabular}{|l|c|c|c|c|c|}
\hline Arrival Mode & Level 1 & Level 2 & Level 3 & Level 4 & Level 5 \\
\hline Ambulance & 54 & 24 & 13 & 7 & 2 \\
\hline Walk-In & 10 & 15 & 27 & 24 & 24 \\
\hline
\end{tabular}

The LOS in the ED is assumed to be triangular, except for patients of level 3.2, which have exponential LOS with mean of 192 minutes. Table 5 shows the parameters involving the LOS for the other kind of patients.

Table 5. LOS in the ED

\begin{tabular}{|c|c|c|c|c|c|}
\hline Level & Min & Mode & Max & Mean (min) & Std. Dev (min) \\
\hline 1 and 2 & 60 & 180 & 600 & 280.00 & 115.76 \\
\hline 3.1 & 120 & 180 & 2400 & 900.00 & 530.47 \\
\hline 3.3 & 60 & 90 & 900 & 350.00 & 194.55 \\
\hline 3.4 & 70 & 90 & 100 & 86.67 & 6.24 \\
\hline 3.5 & 700 & 950 & 1600 & 1083.33 & 189.66 \\
\hline 4.1 & 70 & 80 & 100 & 83.33 & 6.24 \\
\hline 4.2 & 70 & 90 & 100 & 86.67 & 6.24 \\
\hline 5 & 15 & 22 & 30 & 22.33 & 3.06 \\
\hline
\end{tabular}

The last component of the input data is the transfer probability matrix, which is taken from the model in Cochran and Bharti (2006). This matrix shows the probability that a patient is transferred from the ED to any other unit, as well between inpatient units. The information of this matrix implies that $17.89 \%$ of the ED patients are transferred to an inpatient unit.

\section{PHASE 1 EXPERIMENTATION}

\subsection{Experimental Design}

The first part of the experimentation comprises the analysis of the impact of different factors in the performance of the ED. For this purpose, a screening design of the type $2^{3}$ is considered with 5 replications for each combination. Table 6 shows the factors and the values considered for each level. 
Table 6. Factors and Levels Considered for Experimentation in Phase 1

\begin{tabular}{|l|c|c|}
\hline \multicolumn{1}{|c|}{ Factor } & Low Level & High Level \\
\hline A: ED Setting & Regular & Fast-Track \\
\hline B: Number of Beds in the ED & 30 & 40 \\
\hline C: Diversion Threshold (number of patients waiting in the ED) & 30 & 40 \\
\hline
\end{tabular}

Note that in the Fast-Track setting it is required to have separate areas for treating highly acute patients and the less ill ones. In this case, for the low level of factor B, the number of beds in the acute area is 26 and 4 in the fast-track. For the high level, the number of beds in acute area is 32 and 8 in the fast-track.

The response variables to monitor are directly related to the ED performance, and they are the total number of patients treated, the waiting time for all the patients and also by priority (Levels 1\&2, Level 3 and Levels 4\&5), utilization of the ED beds, number of LWOT patients, LWOT percentage, number of hours on diversion, percentage of time on diversion and the number of ambulances diverted. In order to reduce the variance of the performance estimator, the Common Random Numbers technique (Law 2007) is used on each different combination of factor levels.

After a pilot experimentation, it was determined that the run length for each replication is 5040 hours (about 7 months), with the first 504 hours (10\% of total run length) used as a warm-up period. Figure 5 shows the number of patients being treated in the whole hospital for two opposite combinations of factors: all low level and all high levels. This demonstrates that the warm-up length seems to be appropriate for this model.
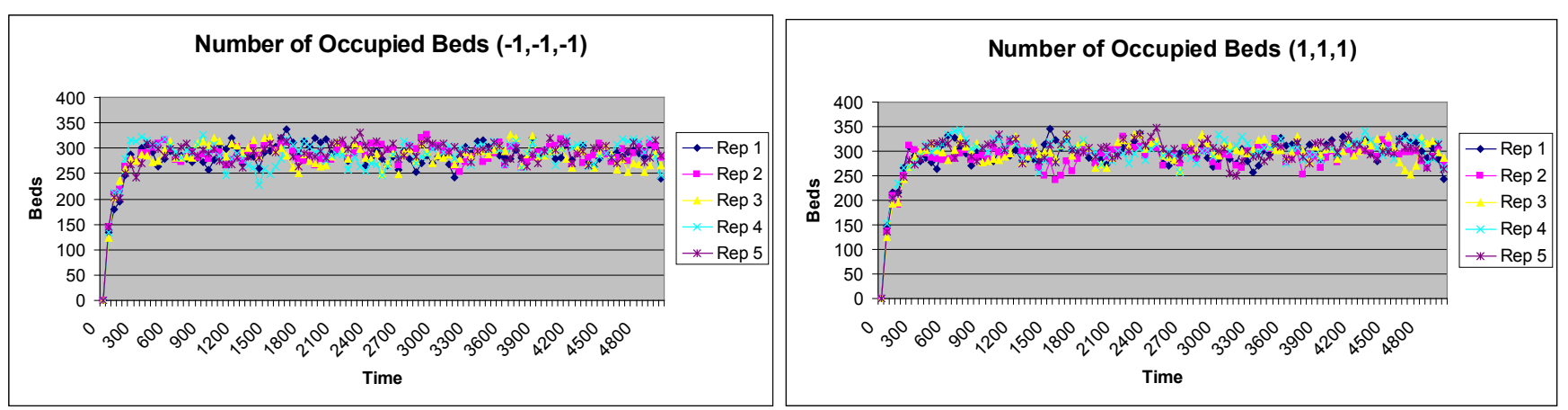

Figure 5. Determination of the Warm-up Length Period of the Simulation

\subsection{Results}

The results of the experiments described before are analyzed through ANOVA and according to them, the number of beds in the ED affects the total number of patients seen, the waiting time of patients of Levels $4 \& 5$ and the LWOT performance. The higher the number of beds, the better is the performance on these responses (as expected). On the other hand, the ED setting affects the utilization of the beds. Furthermore, the "Regular ED" has average higher utilization than a "Fast-Track" under similar circumstances.

In regards on the impact on $\mathrm{AD}$, the significant factors were found to be the ED setting and the Diversion Trigger. According to the results, the best combination of factors that reduces the number of hours on diversion and consequently the percentage of time on diversion is to have a "Fast-Track ED" and the diversion threshold is at the high level. The interactions of these factors have an impact on the diversion performance as well. Table 7 summarizes the results of Phase 1 experimentation.

Note that the results of some of the performance measures are similar to those published in scholarly papers or media articles for hospitals in similar conditions (Cochran and Bharti 2006; Broyles and Cochran 2009; GAO Report 2003; Press Ganey 2007). Additionally, the number of patients seen added to the number of patients LWOT is close to the average number of arrivals for six months, using the data shown in Section 3.2.

The adequacy of all the models for all the responses was checked and each of them (constant variance and independent residuals normally distributed) passed all these assumptions. 
Ramirez, Fowler and $W u$

Table 7. Summary of Results of Phase 1 of Experimentation

\begin{tabular}{|c|c|c|c|c|c|c|c|}
\hline Response & $\begin{array}{l}\text { Significant } \\
\text { Factors }\end{array}$ & $\begin{array}{l}\text { Regression } \\
\text { Equation }\end{array}$ & Mean & $\begin{array}{c}\text { Standard } \\
\text { Deviation }\end{array}$ & $95 \% \mathrm{LL}$ & $95 \% \mathrm{UL}$ & $R^{2}$ \\
\hline Number of Patients Seen & $\mathrm{B}$ & $23102.53+502 \mathrm{~B}$ & 23102.53 & 1091.553 & 20892.79 & 25312.26 & 0.182 \\
\hline $\begin{array}{lll}\begin{array}{l}\text { Global } \\
\text { (hours) }\end{array} & \text { Waiting } & \text { Time } \\
\end{array}$ & None & & 2.48 & 0.43 & 1.61 & 3.35 & \\
\hline $\begin{array}{l}\text { Waiting Time Levels 1-2 } \\
\text { (hours) }\end{array}$ & None & & 0.94 & 0.56 & -0.19 & 2.07 & \\
\hline 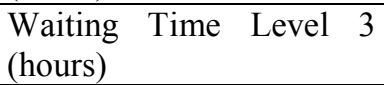 & None & & 2.35 & 0.68 & 0.97 & 3.72 & \\
\hline $\begin{array}{l}\text { Waiting Time Levels } 4-5 \\
\text { (hours) }\end{array}$ & B & 4.45-0.4B & 4.45 & 0.52 & 3.40 & 5.50 & 0.385 \\
\hline Utilization & $\mathrm{A}$ & $90.15-1.5 \mathrm{~A}$ & 90.15 & 2.34 & 85.41 & 94.89 & 0.304 \\
\hline $\begin{array}{l}\text { Total Number of Patients } \\
\text { LWOT }\end{array}$ & B & 5818.45-495B & 5818.45 & 1008.95 & 3775.93 & 7860.96 & 0.202 \\
\hline LWOT Percentage & $\mathrm{B}$ & $20.13-1.71 \mathrm{~B}$ & 20.13 & 3.53 & 12.98 & 27.27 & 0.198 \\
\hline $\begin{array}{l}\text { Total Number of Hours } \\
\text { on Diversion }\end{array}$ & $\mathrm{A}, \mathrm{C}, \mathrm{AC}$ & $\begin{array}{l}206.47-75.5 \mathrm{~A}- \\
101.1 \mathrm{C}+35.5 \mathrm{AC}\end{array}$ & 206.47 & 49.02 & 107.05 & 305.88 & 0.888 \\
\hline $\begin{array}{l}\text { Percentage of Time on } \\
\text { Diversion }\end{array}$ & $\mathrm{A}, \mathrm{C}, \mathrm{AC}$ & $\begin{array}{l}4.2-1.39 \mathrm{~A}-2.1 \mathrm{C}+ \\
0.6 \mathrm{AC}\end{array}$ & 4.2 & 0.98 & 2.21 & 6.18 & 0.887 \\
\hline $\begin{array}{l}\text { Number of Ambulances } \\
\text { Diverted }\end{array}$ & $\mathrm{C}$ & $319.45-153.9$ & 319.45 & 86.82 & 143.69 & 495.20 & 0.768 \\
\hline
\end{tabular}

Note that the highest $\mathrm{R}^{2}$ found are related to the diversion performance. According to these results, the ambulance diversion is reduced by having a "Fast-Track ED" and setting the diversion threshold to the high level. Taking these actions, the number of hours on diversion in the six months simulated is reduced in about 141 hours (more than 5 days, or near $3 \%$ of all the time). This provides a good insight about the actions that could be taken in order to improve ED performance. Nevertheless, a deeper analysis is required, especially in the diversion trigger since the value that this threshold can take is not limited to the ones chosen on this phase.

In order to analyze the effect of choosing the diversion trigger, another experiment phase is conducted, where only the value of the threshold is modified, while the ED setting and the number of beds is fixed to "Fast-Track ED" and 40 respectively, due to the fact that they provide better results for the hospital being simulated.

\section{PHASE 2 EXPERIMENTATION}

\subsection{Experimentation Design}

The second phase of experimentation has the objective of analyzing the impact of several diversion thresholds on the performance of an ED with a fast-track area and subject to 40 beds ( 32 for the acute area and 8 for the fast-track). The designed experimentation with a single factor comprises 5 levels: 30, 40, 50, 60 and 70. Remember that the diversion threshold unit is patients waiting for treatment in the ED.

Six replications are run for each level. Antithetic Random Numbers (Law 2007) are used for every consecutive pair of replications and Common Random Numbers are used between each factor level. The length of the replications and the warmup period are the same as Phase 1 and the duration of each diversion period remains in 30 minutes.

\section{$5.2 \quad$ Results}

The results obtained from the experiment done in Phase 2 implies that the diversion trigger threshold has a significant impact on the global waiting time, the waiting time for patients Levels $1 \& 2$, the number of patients that LWOT, the LWOT percentage, the number of hours on diversion, the percentage of time on diversion and the number of diverted ambulances. Table 8 shows the summary of the results found in Phase 2 and it includes the $95 \%$ Confidence Interval on the mean of the significant responses, as well as the means that are significantly different using a $p$-value $<0.05$ as a threshold. The lower limits in the confidence intervals that produced a negative number are fixed to zero. 
Ramirez, Fowler and Wu

Table 8. Summary of Results Found in Phase 2 (all times in hours)

\begin{tabular}{|c|c|c|c|c|c|c|c|c|}
\hline \multirow[b]{2}{*}{ Response } & \multirow[b]{2}{*}{$95 \% \mathrm{CI}$} & \multicolumn{5}{|c|}{ Diversion Threshold } & \multirow[b]{2}{*}{$\mathrm{R}^{2}$} & \multirow{2}{*}{$\begin{array}{l}\text { Significant Difference } \\
\text { (pair wise comparison) }\end{array}$} \\
\hline & & $1-30$ & $2-40$ & $3-50$ & $4-60$ & $5-70$ & & \\
\hline \multirow{3}{*}{$\begin{array}{l}\text { Global } \\
\text { Waiting } \\
\text { Time }\end{array}$} & LL & 1.42 & 2.33 & 1.79 & 2.06 & 2.85 & \multirow{3}{*}{0.368} & \multirow[t]{3}{*}{$1 \& 2,1 \& 5,3 \& 5$} \\
\hline & Mean & 2.01 & 2.92 & 2.37 & 2.65 & 3.44 & & \\
\hline & UL & 2.59 & 3.51 & 2.96 & 3.23 & 4.03 & & \\
\hline \multirow{3}{*}{$\begin{array}{l}\text { Waiting } \\
\text { Time } \\
\text { Levels 1\&2 }\end{array}$} & LL & 0.00 & 0.86 & 0.18 & 0.79 & 1.96 & \multirow{3}{*}{0.427} & \multirow[t]{3}{*}{$1 \& 5,3 \& 5,4 \& 5$} \\
\hline & Mean & 0.53 & 1.66 & 0.98 & 1.59 & 2.76 & & \\
\hline & UL & 1.34 & 2.46 & 1.78 & 2.39 & 3.56 & & \\
\hline \multirow{3}{*}{$\begin{array}{l}\text { Total } \\
\text { Number } \\
\text { of LWOTs }\end{array}$} & LL & 3672.46 & 5577.13 & 5041.46 & 4732.46 & 5560.96 & \multirow{3}{*}{0.313} & \multirow[t]{3}{*}{$1 \& 2,1 \& 3,1 \& 5$} \\
\hline & Mean & 4625.50 & 6530.17 & 5994.50 & 5685.50 & 6514.00 & & \\
\hline & UL & 5578.54 & 7483.20 & 6947.54 & 6638.54 & 7467.04 & & \\
\hline \multirow{3}{*}{$\begin{array}{l}\text { LWOT } \\
\text { Perrcentage }\end{array}$} & LL & 12.71 & 19.22 & 17.19 & 16.22 & 19.13 & \multirow{3}{*}{0.307} & \multirow[t]{3}{*}{$1 \& 2,1 \& 5$} \\
\hline & Mean & 16.00 & 22.52 & 20.49 & 19.52 & 22.43 & & \\
\hline & UL & 19.30 & 25.82 & 23.79 & 22.82 & 25.73 & & \\
\hline \multirow{3}{*}{$\begin{array}{l}\text { Total } \\
\text { Hours On } \\
\text { Diversion }\end{array}$} & LL & 113.76 & 61.51 & 0.00 & 0.00 & 11.51 & \multirow{3}{*}{0.659} & \multirow{3}{*}{$\begin{array}{l}1 \& 2,1 \& 3,1 \& 4,1 \& 5 \\
2 \& 3,2 \& 4,2 \& 5\end{array}$} \\
\hline & Mean & 144.92 & 92.67 & 21.17 & 26.17 & 42.67 & & \\
\hline & UL & 176.07 & 123.82 & 52.32 & 57.32 & 73.82 & & \\
\hline \multirow{3}{*}{$\begin{array}{l}\text { Diversion } \\
\text { Percentage }\end{array}$} & LL & 2.26 & 1.22 & 0.00 & 0.00 & 0.23 & \multirow{3}{*}{0.659} & \multirow{3}{*}{$\begin{array}{l}1 \& 2,1 \& 3,1 \& 4,1 \& 5 \\
2 \& 3,2 \& 4,2 \& 5\end{array}$} \\
\hline & Mean & 2.88 & 1.84 & 0.42 & 0.52 & 0.85 & & \\
\hline & UL & 3.49 & 2.46 & 1.04 & 1.14 & 1.46 & & \\
\hline \multirow{3}{*}{$\begin{array}{l}\text { Total } \\
\text { Diverted } \\
\text { Ambulances }\end{array}$} & LL & 254.19 & 143.53 & 0.00 & 0.00 & 24.53 & \multirow{3}{*}{0.652} & \multirow{3}{*}{$\begin{array}{l}1 \& 2,1 \& 3,1 \& 4,1 \& 5 \\
2 \& 3,2 \& 4,2 \& 5\end{array}$} \\
\hline & Mean & 326.00 & 215.33 & 46.50 & 59.67 & 96.33 & & \\
\hline & UL & 397.81 & 287.14 & 118.31 & 131.47 & 168.14 & & \\
\hline
\end{tabular}

It can be seen from the table above that the diversion threshold affects not only the diversion performance of the ED, but also the waiting time, especially the global and the waiting time for the most acute patients, as well as the LWOT statistics. In general, it seems that the threshold equals 30 is significantly different from the others. Regarding diversion performance, thresholds 30 and 40 are significant to the rest of the levels.

Setting the diversion trigger to 30 , a better performance in waiting time and LWOT is reached. However, the diversion performance is the worst among the levels analyzed. This is due to the fact that having a low value for triggering the diversion status helps to avoid the congestion in the ED. Therefore, patients do not have to wait too long to get a bed and less patients will leave the ED before receiving treatment.

On the other hand, the diversion performance improves as the diversion threshold is increased, obviously because it takes more time to set the diversion status on. However, the mean value of the number of hours on diversion and percentage of time on diversion increases again after 50. This is likely due to the time required by the system to relief the congestion.

In order to make a decision about diversion threshold, it is necessary to evaluate the problem in a multi-objective fashion. Since correlation exists between global waiting time and waiting time for Levels 1\&2, number of patients LWOT and LWOT percentage, and number of hours on diversion and percentage of time on diversion, the following analysis will be based only on the percentage of time on diversion, the waiting time for the most acute patients and the LWOT percentage. Figure 6 shows the objective space using a bi-criteria graph.

Looking at the results, there seems to exists a tradeoff between diversion performance and other measures, such as waiting time and LWOT. Furthermore, not all the diversion thresholds provide good responses. For instance, it can be seen from the figure shown above, that if the percentage of time on diversion and the waiting time of the acutest levels of trauma are considered, the supported Pareto Optimal solutions for this specific case are: 50 and 30. If LWOT percentage is considered instead of waiting time, then the supported Pareto Optimal are 50,60 and 30. 

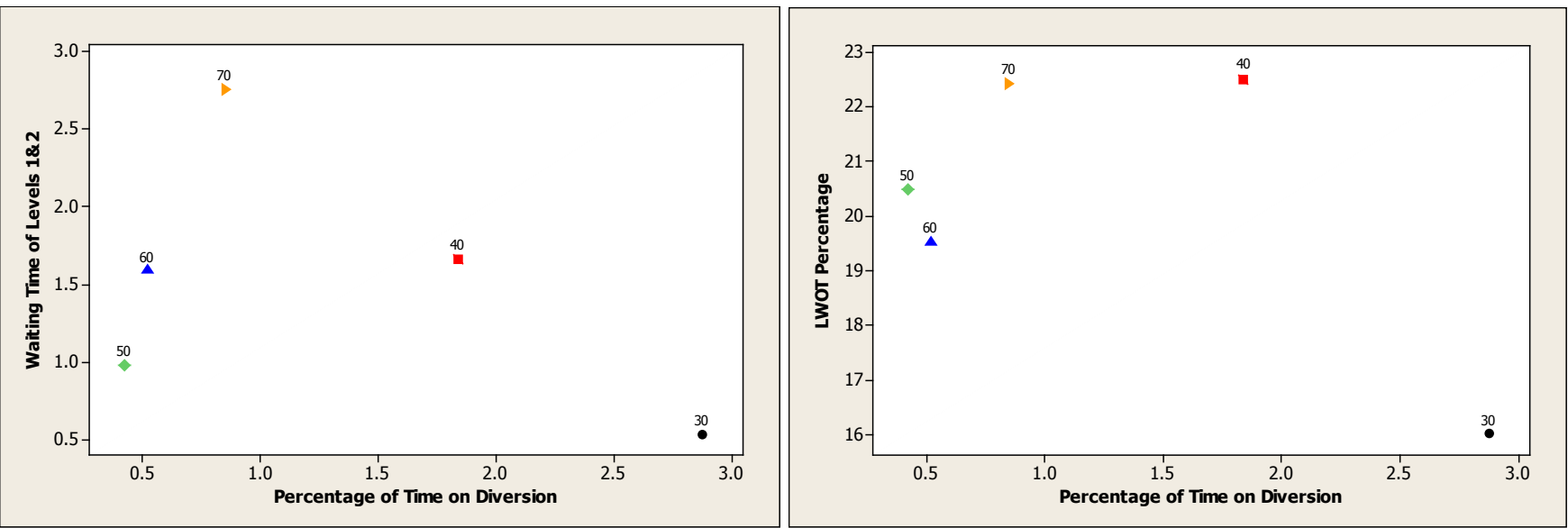

Figure 6. Objective Space Considering Percentage of Time on Diversion versus Waiting Time of Levels 1\&2 (left) and LWOT Percentage (right)

Choosing a threshold that minimizes the waiting time and the LWOT percentage will cause that the time on diversion increases (threshold $=30$ ). However, minimizing the percentage of time on diversion does not provide the maximum waiting time or LWOT percentage (thresholds $=50$ or 60). Actually, the performance of those values does not seem to be bad at all. In order to consider the variation in the results, another similar graph is shown in Figure 7, considering now the mean value for each replication at each level.

Analyzing this graph, there is a clear difference in the variation degree for each level. The results that are closer to the origin (thresholds 50 and 60) have means closer to each other than the other thresholds (30,40 and 70). This indicates that for this model, under the conditions considered, thresholds of 50 and 60 provide good performance on diversion, LWOT and waiting time, which also provides a small variation, allowing a better prediction capability.

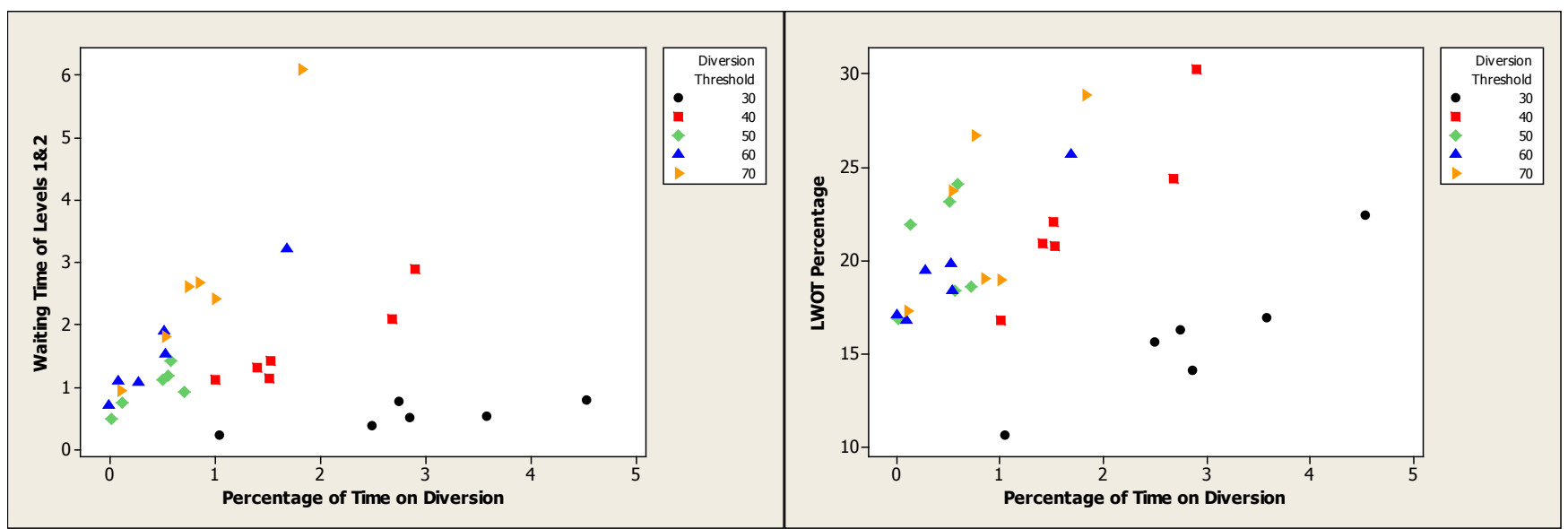

Figure 7. Objective Space Considering Percentage of Time on Diversion versus Waiting Time of Levels 1\&2 (left) and LWOT Percentage (right) taking into account the mean of each replication

So far, the boarding problem has not been analyzed on this problem, however, literature suggests that there is a correlation between the number of patients boarding in the ED and the diversion status (Burt and McCaig 2004). In order to analyze this situation, a figure of the number of patients boarding when it was decided to set the diversion status on is built, and it is shown in Figure 8.

The last figure indicates that there is a high number of patients boarding in the ED waiting for a bed in an inpatient unit when the diversion status is set on. This might be one root cause of the congestion of the ED that finally contributes not only to the diversion, but also to leaving without treatment and having long waiting times. However, the boarding problem is not caused by all the inpatients units. According to the graph shown in the right hand side of Figure 8, most of the patients boarding in the ED are waiting to be transferred to Oncology, Renal, Surgery or Telemetry 1. Therefore, a global solution should include some actions on the capacity of those units. 

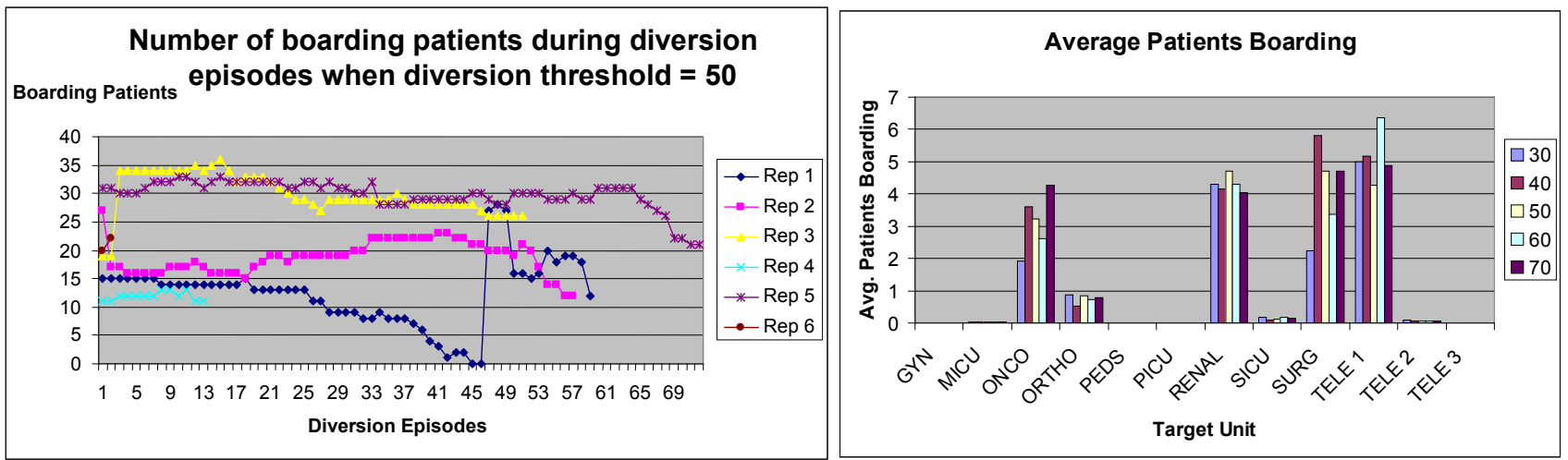

Figure 8. Number of Patients Boarding During Each Diversion Episode When Threshold $=50$ (left) and Average Number of Patients Boarding According to their Target Unit for all Thresholds (right)

\section{CONCLUSIONS AND FUTURE RESEARCH}

This paper analyzes the performance measures in the ED of a large-size hospital, using data provided by published papers. Furthermore, the impact of the ED setting, the number of beds and the diversion threshold were studied using a simulation model. Results show that a hospital with the characteristics modeled performs better with a fast-track area dedicated to less acute ED patients.

However, the most interesting findings rely on the effect of the diversion threshold on the performance of the ED. The results suggest that there is a trade-off between diversion performance and other measurements, such as waiting time and LWOT. This implies that in order to reduce congestion of the system, patients will have to avoid joining the system either by diversion or leaving before treatment. Nevertheless, it seems that a diversion threshold that can provide a good performance over other policies and that also produces consistent behavior exists.

Due to the lack of studies on diversion policies, this part of the research will serve as the basis to design a methodology to obtain an appropriate threshold that can improve the performance of the emergency system under a diversity of situations.

Note that one of the advantages of this experimentation is the robustness of the model built, since it includes a wide variety of inputs, path flows, interaction among departments and seasonal patterns. This level of detailed is not common in similar models found in the literature. Therefore, the possibility to characterize different types of hospitals into a model with this level of detail is a challenge that will be part of the future research.

\section{REFERENCES}

Asplin, B.R. 2003. Does ambulance diversion matter?. Annals of Emergency Medicine/Editorial. 2003. 41:477-480.

Associated Press. 2006. Press Report: ER care in US at 'breaking point'. Available via $<$ http://www.msnbc.msn.com/id/13320317/from/ET/> [accessed May 8, 2009].

Brailsford, S.C. 2008. System dynamics: What's in it for healthcare simulation modelers. In Proceedings of the 2008 Winter Simulation Conference, ed. S.J. Mason, R.R. Hill, L. Monch, O. Rose. T. Jefferson, and J.W. Fowler. 1478-1483. Piscataway, New Jersey: Institute of Electrical and Electronics Engineers, Inc.

Broyles, J.R., and J.K. Cochran. 2007. Estimating business loss to a hospital emergency department from patient reneging by queuing-based regression. In Proceedings of the 2007 Industrial Engineering Research Conference, ed. G. Bayraksan, W. Kin, Y. Son, and R. Wysk.

Burt, C.W., and L.F.McCaig. Staffing, capacity and ambulance diversion in emergency departments: United States, 20032004. Advance Data from Vital and Health Statistics of the CDC.

Burt, C.W., L.F. McCaig and R.H. Valverde. 2006. Analysis of ambulance transports and diversions among US emergency departments. Annals of Emergency Medicine.47:317-326.

Cochran, J.K., and A. Bharti. 2006. A multi-stage stochastic methodology for whole hospital bed planning under peak loading. International Journal of Industrial and Systems Engineering. 1:8-36.

Cochran, J.K., and K.T. Roche. 2009. A multi-class queueing network analysis methodology for improving hospital emergency department performance. Computers and Operations Research. 36:1497-1512. 
Ferrin, D.M., M.J. Miller, and D.L. McBroom. 2007. Maximizing hospital financial impact and emergency department throughput with simulation. In Proceedings of the 2007 Winter Simulation Conference, ed. S.G. Henderson, B. Biller, M.-H. Hsieh, J. Shortle, J.D. Tew, and R.R. Barton 1566-1573. Piscataway, New Jersey: Institute of Electrical and Electronics Engineers, Inc.

Huang, D.T. 2004. Clinical review: Impact of emergency department care on intensive care unit costs. Review in Critical Care. 8:498-502.

Kolb, E.M.W., J. Peck, S. Schoening, and T. Lee. 2008. Reducing emergency department overcrowding-five patient buffer concepts in comparison. In Proceedings of the 2008 Winter Simulation Conference, ed. S.J. Mason, R.R. Hill, L. Monch, O. Rose. T. Jefferson, and J.W. Fowler. 1478-1483. Piscataway, New Jersey: Institute of Electrical and Electronics Engineers, Inc.

Law, A.M. 2007. Simulation modeling \& analysis. $4^{\text {th }}$ ed. McGraw-Hill, Inc.

McConnell, K.J., C.F. Richards, M. Daya, C.C. Weathers, and R.A. Lowe. 2006. Ambulance diversion and lost hospital revenues. Annals of Emergency Medicine. 48:702-710.

Medeiros, D.J., E. Swenson, and C. DeFlitch. 2008. Improving patient flow in a hospital emergency department. In Proceedings of the 2008 Winter Simulation Conference, ed. S.J. Mason, R.R. Hill, L. Monch, O. Rose. T. Jefferson, and J.W. Fowler. 1478-1483. Piscataway, New Jersey: Institute of Electrical and Electronics Engineers, Inc.

National Academy of Engineering and Institute of Medicine. 2005. Building a better delivery system. A new engineering/health care partnership. The National Academies Press.

Press Ganey Associates. 2007. Emergency Department Pulse Report.

Roche, K.T., and J.K. Cochran. 2007. Improving patient safety by maximizing fast-track benefits in the emergency department-a queuing network approach. In Proceedings of the 2007 Industrial Engineering Research Conference, ed. G. Bayraksan, W. Kin, Y. Son, and R. Wysk.

Ramirez, A., J.W. Fowler, and T. Wu. 2009. Modeling of regional healthcare delivery networks using distributed simulation. In Proceedings of the 2009 Industrial Engineering Research Conference, ed. J. C. Smith, and J. Geunes.

United States General Accounting Office. 2003. Hospital Emergency Departments. Crowded conditions vary among hospitals and communities.Report to US Senate.

Upfold, J. 2002. Emergency department overcrowding: ambulance diversion and the legal duty to care. Commentary in the Canadian Medical Association Journal. 166:445-446.

US Department of Health and Human Services, National Health Expenditure. Available via $<$ http://www.cms.hhs.gov/NationalHealthExpendData/> [accessed May 4, 2009].

\section{AUTHOR BIOGRAPHIES}

ADRIAN RAMIREZ is a PhD student in the Department of Industrial, Systems and Operations Engineering at Arizona State University. His research interests include modeling, simulation and analysis of healthcare delivery systems. He received a MS in Manufacturing Systems at ITESM and a BS in Industrial Engineering at Universidad de Sonora, both in Mexico. His email address is <adrian.ramirez@asu.edu>.

JOHN W. FOWLER is a Professor in the Operations Research and Production Systems group of the Department of Industrial, Systems and Operations Engineering at Arizona State University. His research interests include modeling, analysis, and control of manufacturing and service systems. He is a Fellow of the Institute of Industrial Engineers and is the SCS representative on the Board of Directors of the Winter Simulation Conference. He is an Area Editor of the Transactions of the Society for Computer Simulation International, an Associate Editor of IEEE Transactions on Semiconductor Manufacturing, and will be the Editor of a new journal entitled IIE Transactions on Healthcare Systems Engineering. His email address is $<j o h n$. fowlereasu.edu>.

TERESA WU is an Associate Professor of the Department of Industrial, Systems and Operations Engineering at Arizona State University. She received her Ph.D. in Industrial Engineering from the University of Iowa in 2001. Her current research interests include: distributed decision support, distributed information system, supply chain modeling and disruption management. Professor Wu has over 30 articles published (or accepted) in such journals as International Journal of Production Research, Omega, Data and Knowledge Engineering and ASME: Journal of Computing and Information Science in Engineering, IEEE Transactions on Engineering Management. She serves on the Editorial Review Board for International Journal of Production Research, IEEE Transactions on Engineering Management, Computer and Standard Interface, International Journal of Electronic Business Management. Her email address is <teresa . wueasu. edu>. 